Article

\title{
Consumers' Willingness to Pay for Net-Zero Energy Apartment in South Korea
}

\author{
Ju-Hee Kim, Hyo-Jin Kim and Seung-Hoon Yoo * \\ Department of Energy Policy, Graduate School of Energy \& Environment, Seoul National University of Science \\ \& Technology, 232 Gongreung-Ro, Nowon-Gu, Seoul 01811, Korea; jhkim0508@seoultech.ac.kr (J.-H.K.); \\ hjinkim@seoultech.ac.kr (H.-J.K.) \\ * Correspondence: shyoo@seoultech.ac.kr; Tel.: +82-2-970-6802
}

Received: 8 March 2018; Accepted: 10 May 2018; Published: 14 May 2018

\begin{abstract}
In South Korea, buildings account for more than 25\% of the nation's total greenhouse gas emissions. Therefore, the government aims to make zero energy buildings mandatory from 2025, onward. For the housing sector, the government has recently built and operated a pilot net-zero energy apartment (NZEA) and plans to expand it to several cities. This article attempts to obtain information about the consumers' willingness to pay (WTP) for the NZEAs. To this end, households' additional WTP for the NZEAs over a conventional apartment was investigated, applying the contingent valuation (CV) approach. The data on the WTP were gathered from a CV survey of 1000 interviewees and analyzed, employing a dichotomous choice question and the spike model, respectively. The mean value of the additional WTP is obtained as KRW 0.46 million (USD 424) per $\mathrm{m}^{2}$, which is statistically significant. This value corresponds to $17.0 \%$ of the conventional apartment price per $\mathrm{m}^{2}$ (KRW 2.76 million, USD 2436). It can be concluded that the households in South Korea place a significant value on a NZEA over a conventional apartment. In addition, we have investigated the characteristics of consumers which affect the probability that consumers accept additional payment of an amount of money for NZEA over a conventional apartment, finding that higher income earners, higher education, and male consumers have a higher probability.
\end{abstract}

Keywords: net-zero energy apartment; willingness to pay; contingent valuation

\section{Introduction}

Abating greenhouse gas (GHG) emissions has already become a crucial issue around the world. The average global temperature has increased by 0.85 in the past 133 years (1880-2012), according to current trends, the global mean temperature is expected to rise by 2.6 to $4.8^{\circ} \mathrm{C}$ at the end of the $21 \mathrm{st}$ century and the sea level to rise by 45 to $82 \mathrm{~cm}$ [1]. As a result, the world has set specific goals and made efforts through the Kyoto protocol in 1997 and the Paris climate change accord in 2015 to reduce GHG emissions, which are considered one of the major factors of climate change.

South Korea has been ranked the second in growth rate of GHG emissions in the OECD countries since 2000 and is currently the fifth largest GHG emitter [2]. Therefore, South Korea pledged to mitigate GHG emissions by 37\% from business as usual (BAU) by 2030 in the Paris Climate Change Accord in 2015. Presently, the South Korean government has implemented various policies to reduce GHG emissions. In particular, a quarter of the nation's GHG emissions are from the building sector [3]. The government announced a policy of reducing GHG emissions and energy consumption by mandating zero energy building (ZEB) construction from 2025, onward.

According to United States Department of Energy and International Energy Agency, a ZEB is a residential or commercial building that minimizes energy requirements through building energy 
efficiency. As buildings consume 36\% of the world's energy consumption [4], countries around the world recognize ZEB as a solution to energy saving and various studies are being carried out [5-9].

Zero energy apartments (ZEAs) are residential ZEBs, energy-independent apartments designed to reduce carbon emissions from energy consumption to zero. ZEAs maximize the insulation performance of the building, minimize the energy consumption of the home, and utilize renewable energy to supply the energy needed for building functions. As a result, ZEAs' energy consumption and GHG emissions are expected to be reduced by $90 \%$ and $75 \%$, respectively, compared to conventional apartments [3]. However, it is not possible to supply enough energy by time and season, year by year, of renewable energy production facilities alone, or it can cause very large cost increase.

In South Korea, an apartment system has been developed that connects conventional urban energy supply networks, uses non-renewable energy at necessary times, and transmits energy to the supply network at the time when the generated energy is unnecessary. As a result, the apartment's annual energy balance contrast is zero, and the energy requirement is reduced by $60 \%$ compared to the conventional apartment. It is called a net-ZEA (NZEA). Currently, the South Korean government has built and piloted NZEA, and plans to expand it to several new cities. However, the NZEA requires greater construction costs than conventional apartments. Moreover, government officials are asking for information about the value that the enforcement of the NZEA construction policy produces to the consumer, which is of great help to obtain some implications concerning whether the NZEA construction should be performed or not.

There are many studies on technological improvements of ZEBs. For example, see Mohammad et al. [5], Bühler et al. [6], Koller et al. [7], Marszal et al. [8], and Wang et al. [9]. However, a few studies analyzed consumers' preferences for ZEBs. For instance, Li et al. [10] examined market acceptability of net-zero energy homes (NZEH) in Canada, proposed a holistic framework to analyze stakeholders for NZEHs, and presented strategies that could be applied to promoting NZEHs. In addition, the study reveals that $77 \%$ of the homebuyer survey respondents indicated an interest in buying an NZEH and half of the potential NZEH homebuyers showed a willingness to accept a $5 \%$ increase in price compared to conventional homes. The other half of respondents are made up of four categories: (i) those who reported a willingness to pay (WTP) up to $10 \%$ more (10\%); (ii) those who reported a WTP up to $15 \%$ more $(10 \%)$; (iii) those who reported a WTP up to $20 \%$ more (20\%); and (iv) those who answered that their decision depends on return $(10 \%)$.

There are four differences between Li et al.'s [10] study and ours. First, the former dealt with the Canadian case, but the latter will use the specific case of South Korea. Second, the former gathered just 69 responses using an Internet-based survey, while the second collected 1000 responses from a nationwide survey using person-to-person interviewing implemented from a professional survey company. Third, although the former presented just a descriptive distribution of the WTP, our study will estimate the distribution function of the WTP and report the estimates for its parameters. Finally, the former did not derive the mean WTP for NZEH, though the second will compute the mean WTP for NZEAs, which is necessary for analyzing consumers' welfare arising from expanding the supply of the NZEA, employing a random utility maximization model.

Information on the WTP for NZEA is useful for decision-making in building NZEAs. This is because nations continue to make investments in NZEAs, which constitute one of the most important components of their budget for public infrastructure. Economic evaluation is important because it aids in ascertaining whether the public favors proposed projects for the constructing NZEA and in estimating the degree to which it is willing to pay for benefits. In the prevalent context of constrained public budgets, conceptually correct and empirically valid estimates of the consumers' WTP for NZEAs are essential for making economically sound investment decisions.

The main objective of this paper is to estimate the consumer's WTP for NZEAs in South Korea. For this purpose, this study strives to derive household additional WTP for a NZEA over a conventional apartment. The rest of this article consists of four sections. Section 2 describes the methodology that this article adopts. Modeling of the WTP data is explained in Section 3. The fourth section provides the results are the discussion of them. The final section presents conclusions. 


\section{Methodology}

\subsection{Object to Be Evaluated}

As addressed above, increasing GHG emissions in South Korea have become a critical problem and effective and rigorous policies should be taken to reduce the GHG emissions. Thus, the government seeks to expand the supply of the NZEA. NZEAs use high-performance insulation materials and sunshades to minimize the use of household cooling and heating energy. Additionally, the use of the eco-friendly energy more than conventional fossil fuels makes it possible to dramatically reduce GHG emissions.

In addition, the government is trying to expand the supply of the NZEAs. The betterment goal of the presented policy is to expand the construction of the NZEAs using various policy instruments and mandate it from 2025, onward. The main policy instrument, which was conveyed and explained to the respondents through using newspaper articles, color pictures, and well-made presentation materials during the contingent valuation (CV) survey is to build a NZEA town in a new city, such as Sejong Special Self-governing City, based on the currently-operated NZEA demonstration complex. Thus, the government requires the quantitative information about the consumers' WTP for the NZEA. This article attempts to evaluate the consumers' additional WTP for the NZEA over a conventional apartment in terms of the price of an apartment per $\mathrm{m}^{2}$.

\subsection{Method: $\mathrm{CV}$}

From the literature review, it is found that stated preference (SP) methods have been usually applied to carrying out the measurement of the consumers' WTP. The SP methods usually ask people to state their WTP for consuming the goods or services concerned. Two representative approaches belonging to SP methods are the CV approach and choice experiment (CE) approach e.g., [11-17]. The former elicits the WTP response directly. However, the latter derives the WTP responses indirectly. This study will employ the CV approach instead of the CE approach because the first is much simpler to apply than the second and the attributes required in using the $\mathrm{CE}$ approach are not well defined in this study.

Our research can be compared with the previous studies in four points. First, the studies that measured people's WTP for NZEA remain scarce. Most of related studies have tackled energy saving and renewable energy [18-20]. In this regard, this study can contribute to the literature on the consumers' evaluation of a NZEA. In particular, there is no former research that measured the consumers' WTP for a NZEA in other countries as well as South Korea.

Second, our application of the CV technique coincides with the practice adopted in the former studies dealing with this kind of research topic. Moreover, the CV technique is based on microeconomics and is, thus, theoretically sound [21]. Since the findings obtained in this article can be used in policy-making and analysis, it is crucial to use reasonable and sound methodology. The CV technique is not only practically useful, but also theoretically robust.

Third, we tried to follow several guidelines recommended for applying the CV approach in the literature. They include the use of a dichotomous choice (DC) question, a minimum sample size of 1000 , the announcement of the possible presence of substitutes for the goods to be investigated in the $\mathrm{CV}$ survey, and so on. More details will be presented in the next subsections.

Fourth, when eliciting the WTP responses this study paid more attention to not only mitigating the response bias, but also to augmenting the statistical efficiency. The respondents are asked just one question in the single-bounded (SB) DC method. Hence, it may suffer from low statistical efficiency. The double-bounded (DB) DC method, which requires two WTP questions, may suffer from the response bias. As an alternative, Cooper et al. [22] contrived a one-and-one-half-bounded (OOHB) DC method. It can produce more efficient results than the SB DC method and cause less response bias than the DB DC method. Furthermore, the spike model proposed by Kriström [23] is combined with the OOHB DC method in order to model the WTP data with zero observations. 


\subsection{Sampling and Survey Instrument}

As mentioned above, the government will mandate ZEB and NZEA for all buildings built nationwide from 2025, onward. Therefore, 1000 households were sampled nationwide based on the demographic characteristics reported by Statistics Korea [24]. In this regard, our sampling method was stratified random sampling. The entire process of sampling and carrying out the survey was administered by a professional polling company during September 2017. The firm sough to make sure that the sample characteristics represents the population characteristics well. An experienced specialist at the firm ran the whole process.

A pretest using a focus group of thirty persons was implemented with an earlier version of the survey instrument to examine whether it is understandable and clear enough for the interviewees to finish filling in the survey questionnaire or not. The outcomes of the in-depth interviews with the focus group have been utilized to make the questionnaires fully corrected for the use in the main survey. The final version of the survey questionnaire is made up of four parts. The first part presents the background and objective of the survey. The second part includes several questions deriving the interviewees' opinions and judgment regarding the policy of building NZEAs. The third part deals with the questions about the additional WTP for living in a NZEA rather than a conventional apartment. Some questions about respondents' characteristics are given in the final part.

\subsection{Elicitation of WTP}

As explained above, this article adopted an OOHB DC question for the purpose of eliciting the WTP responses. The DC question was originally recommended for the use in the field CV survey by a number of studies. The main reason for the recommendation is that it can reduce the respondents' burden of answering the WTP question and derive an incentive-compatible response from interviewees [25]. The DC question is quite simple. The only work for a respondent must do is to state "yes" or "no" to a given bid amount. The respondent will report "yes" if her/his additional WTP for purchasing a NZEA over a conventional apartment is more than, or equal to, an offered bid and "no", otherwise. On the other hand, an open-ended question of directly asking the WTP value is not preferred to the DC question in the literature because the former can induce a number of protest WTP responses $[26,27]$. The OOHB DC format has the merit of taking only the preferential features of the SB and DB DC formats.

One complication involved in applying the $\mathrm{CV}$ is that it puts people in a hypothetical situation and, thus, the respondents can have difficulties in stating their true WTP. An appropriate payment can help the respondents confronted with the hypothetical situation to report their WTP making them feel as if they were in the real world. Some examples of the payment vehicle include a tax, such as income tax or property tax, a donation, a fund, a usage fee, and so on. The payment vehicle should be directly related to the object to be evaluated and be familiar to people.

We decided that the payment vehicle meeting the two conditions is the additional price of a NZEA built in Sejong Special Self-governing City, a recently-developed and typically new city in South Korea over a conventional apartment built in the same area. The price is expressed as Korean won per pyeong, which is same as $3.3 \mathrm{~m}^{2}$. The unit of 'pyeong' is more frequently used in South Korea than that of ' $\mathrm{m}^{2}$ '. Consequently, the WTP question presented to the respondents was "Would your household accept an amount of increase in the price of an apartment per pyeong $\left(=3.3 \mathrm{~m}^{2}\right)$ for the purpose of living in a NZEA rather than a conventional apartment?"

\section{WTP Model}

\subsection{OOHB DC Model}

Cooper et al. [22] proposed an approach to model the OOHB DC CV data. $A_{j}$ is defined as a bid presented to respondent $j$. Before implementing the field $C V$ survey, we need to determine several sets of two bids, $A_{j}^{L}$ and $A_{j}^{U}\left(A_{j}^{L}<A_{j}^{U}\right)$. A set is randomly selected of the several sets and presented 
to each interviewee. Each set is composed of $A_{j}^{L}$ and $A_{j}^{U}$. About half of respondents in a group who receive the same set are asked to state "yes" or "no" to the payment of $A_{j}^{L}$. If the response is "yes", an additional question about whether they are willing to pay $A_{j}^{U}$ or not is asked. If the response to the payment of $A_{j}^{L}$ is "no," the additional question is needless. The other half of the respondents are confronted with a question about the payment of $A_{j}^{U}$. If the response is "no", a follow-up question about whether they are willing to pay $A_{j}^{L}$ or not is asked. If the response to the payment of $A_{j}^{U}$ is "yes," the follow-up question is not required.

Let $Y_{j}$ be the interviewee's WTP. Three responses, "yes-yes" $\left(Y_{j}>A_{j}^{U}\right)$, "yes-no" $\left(A_{j}^{L}<Y_{j}<A_{j}^{U}\right)$, and "no" $\left(Y_{j}<A_{j}^{L}\right)$ can emerge from the situation where $A_{j}^{L}$ is offered at first. One of three responses, "yes" $\left(Y_{j}>A_{j}^{U}\right)$, "no-yes" $\left(A_{j}^{L}<Y_{j}<A_{j}^{U}\right)$, and "no-no" $\left(Y_{j}<A_{j}^{L}\right)$, can occur in the case that $A_{j}^{U}$ is provided at first. Therefore, there can be six kinds of responses. Let $I_{j}^{Y Y}, I_{j}^{Y N}, I_{j}^{N}, I_{j}^{Y}, I_{j}^{N Y}$, and $I_{j}^{N N}$ be binary variables which correspond to the six kinds of responses. For instance, $I_{j}^{Y Y}$ is one if $j$ th interviewee reports "yes-yes" and zero otherwise.

$$
\begin{gathered}
I_{j}^{Y Y}=\mathbf{1}(j \text { th respondent's response is "yes-yes" }) \\
I_{j}^{Y N}=\mathbf{1}(j \text { th respondent's response is "yes-no" }) \\
I_{j}^{N}=\mathbf{1}(j \text { th respondent's response is "no" }) \\
I_{j}^{Y}=\mathbf{1}(j \text { th respondent's response is "yes" }) \\
I_{j}^{N Y}=\mathbf{1}(j \text { th respondent's response is "no-yes" }) \\
I_{j}^{N N}=\mathbf{1}(j \text { th respondent's response is "no-no" })
\end{gathered}
$$

where $\mathbf{1}(\cdot)$ is an indicator function whose value is one when the argument is true and zero otherwise.

\subsection{Combination of the OOHB DC Question and Spike Model}

An additional question, "Would your household agree to pay anything?", was given to the respondents who reported "no" response to the lower bid or "no-no" response to the upper bid. Her/his WTP is less than the lower bid and more than zero if the answer is "yes." Her/his WTP is zero if the answer is "no." One more binary variable, $I_{j}^{T Y}$, is defined as one if the answer is "yes" and zero otherwise. Thus, there are eight outcomes:

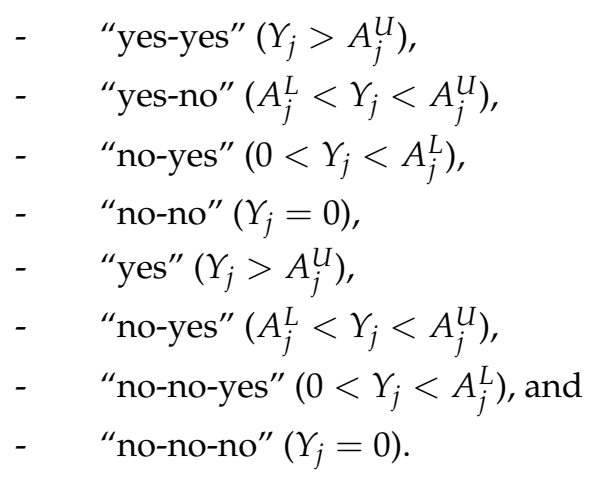

where the first four outcomes are achieved when $A_{j}^{L}$ is offered first and the latter four outcomes are obtained when $A_{j}^{U}$ is supplied first.

As will be explained below, out of the 1000 respondents, 595 said they had no intention of paying a penny. Thus, the spike model can be usefully employed to deal with the WTP data. Considering that 
the most-frequently used distribution in analyzing the DC CV data is logistic distribution, we specify the WTP distribution function, $F_{Y}(\cdot)$, as:

$$
F_{Y}\left(A ; \gamma_{0}, \gamma_{1}\right)= \begin{cases}{\left[1+\exp \left(\gamma_{0}-\gamma_{1} A\right)\right]^{-1}} & \text { if } A>0 \\ {\left[1+\exp \left(\gamma_{0}\right)\right]^{-1}} & \text { if } A=0 \\ 0 & \text { if } A<0\end{cases}
$$

where $\gamma_{0}$ and $\gamma_{1}$ are the parameters of $F_{Y}(\cdot), A$ means the independent variable of $F_{Y}(\cdot)$, and $\exp (\cdot)$. is exponential function.

The log-likelihood function we deal with is:

$$
\begin{aligned}
\ln L= & \sum_{j=1}^{S}\left\{\left(I_{j}^{Y}+I_{j}^{Y Y}\right) \ln \left[1-F_{Y}\left(A_{j}^{U} ; \gamma_{0}, \gamma_{1}\right)\right]\right. \\
& +\left(I_{j}^{Y N}+I_{j}^{N Y}\right) \ln \left[F_{Y}\left(A_{j}^{U} ; \gamma_{0}, \gamma_{1}\right)-F_{Y}\left(A_{j}^{L} ; \gamma_{0}, \gamma_{1}\right)\right] \\
& +I_{j}^{T Y}\left(I_{j}^{N}+I_{j}^{N N}\right) \ln \left[F_{Y}\left(A_{j}^{L} ; \gamma_{0}, \gamma_{1}\right)-F_{Y}\left(0 ; \gamma_{0}, \gamma_{1}\right)\right] \\
& \left.+\left(1-I_{j}^{T Y}\right)\left(I_{j}^{N}+I_{j}^{N N}\right) \ln F_{Y}\left(0 ; \gamma_{0}, \gamma_{1}\right)\right\}
\end{aligned}
$$

where $S$ is the sample size, $\gamma_{0}$ and $\gamma_{1}$ are the parameters of $F_{Y}(\cdot)$, and $I_{j}^{Y Y}, I_{j}^{Y N}, I_{j}^{N}, I_{j}^{Y}, I_{j}^{N Y}$, and $I_{j}^{N N}$ are defined in Equation (1).

We can obtain the estimates for $\gamma_{0}$ and $\gamma_{1}$ by finding the values for $\gamma_{0}$ and $\gamma_{1}$ maximizing Equation (2), that is, using the maximum likelihood estimation method. When using Equation (1) and the estimates for $\gamma_{0}$ and $\gamma_{1}$, the average WTP can be obtained as:

$$
E(Y)=\int_{0}^{\infty}\left[1-F_{Y}\left(A ; \gamma_{0}, \gamma_{1}\right)\right] d A-\int_{-\infty}^{0} F_{Y}\left(A ; \gamma_{0}, \gamma_{1}\right) d A=\left(1 / \gamma_{1}\right) \ln \left[1+\exp \left(\gamma_{0}\right)\right]
$$

where $\gamma_{0}$ and $\gamma_{1}$ are the parameters of $F_{Y}(\cdot), A$ means the independent variable of $F_{Y}(\cdot)$, and $\exp (\cdot)$ is exponential function.

\section{Results and Discussion}

\subsection{Data}

USD 1.0 was equal to KRW 1132 when the survey was performed. The list of sets of $A_{j}^{L}$ and $A_{j}^{U}$ used in the CV survey is $250 / 350,300 / 400,350 / 450,450 / 550,550 / 650,650 / 750$, and $800 / 900$ ten thousand KRW per pyeong $\left(=3.3 \mathrm{~m}^{2}\right)$. They were determined through the focus group interview of thirty individuals as follows: first, we asked the WTP for the enforcement and obtained a set of WTP values; second, we deleted zero WTP values and then sorted the remaining positive WTP values to look into empirical distribution; third, some bids were selected from the distribution. One of the seven sets of $A_{j}^{L}$ and $A_{j}^{U}$ was randomly offered to the interviewees.

Finally, 1000 usable observations were obtained from the CV survey. Table 1 reports a summary of the interviewees' responses to each set of bids. Overall, 29, 45, 126, and 300, 52, 24, 129, and 295 interviewees gave "yes-yes", “yes-no", "no-yes", "no-no", “yes", "no-yes", "no-no-yes", and "no-no-no" responses, respectively. Out of the 1000 respondents, 595 said they had no intention of paying a penny ("no-no" and "no-no-no" responses). 
Table 1. Summary of the interviewees' responses to each set of bids.

\begin{tabular}{|c|c|c|c|c|c|c|c|c|c|c|}
\hline \multirow{2}{*}{\multicolumn{2}{|c|}{ Bid Amount ${ }^{a}$}} & \multicolumn{4}{|c|}{ Lower Bid Is Offered at First $(\%) b$} & \multicolumn{4}{|c|}{ Upper Bid Is Offered at First (\%) ${ }^{b}$} & \multirow{2}{*}{$\begin{array}{c}\text { Sample } \\
\text { Size }\end{array}$} \\
\hline & & "Yes-Yes" & "Yes-No" & "No-Yes" & "No-No" & "Yes" & "No-Yes" & "No-No-Yes" & "No-No-No" & \\
\hline 250 & 350 & $4(2.8)$ & $10(7.0)$ & $16(11.2)$ & $42(29.4)$ & $10(7.0)$ & $3(2.1)$ & $16(11.2)$ & $42(29.4)$ & $143(100.0)$ \\
\hline 350 & 450 & $6(4.2)$ & $10(7.0)$ & $12(8.4)$ & $43(30.1)$ & $10(7.0)$ & $2(1.4)$ & $18(12.6)$ & $42(29.4)$ & $143(100.0)$ \\
\hline 450 & 550 & $3(2.1)$ & $4(2.8)$ & $21(14.7)$ & $44(30.8)$ & $7(4.9)$ & $5(3.5)$ & $20(14.0)$ & $39(27.3)$ & $143(100.0)$ \\
\hline 550 & 650 & $4(2.8)$ & $6(4.2)$ & $17(12.0)$ & $44(31.0)$ & $13(9.2)$ & $6(4.2)$ & $19(13.4)$ & $33(23.2)$ & $142(100.0)$ \\
\hline 650 & 750 & $4(2.8)$ & $1(0.7)$ & $18(12.7)$ & $48(33.8)$ & $5(3.5)$ & $1(0.7)$ & 18 (12.7) & $47(33.1)$ & $142(100.0)$ \\
\hline
\end{tabular}

Notes: ${ }^{\text {a }}$ The unit is tens of thousands of Korean won (USD 1.0 = KRW 1132 at the time of the survey) per pyeong $\left(=3.3 \mathrm{~m}^{2}\right) \cdot{ }^{\mathrm{b}}$ A percentage of sample size is given in parentheses beside the number of responses.

\subsection{Estimation Results of the Model}

Table 2 presents the estimation results of the model. The estimates for $\gamma_{0}$ and $\gamma_{1}$ are all statistically significant. In particular, a negative sign of the estimate for $\gamma_{1}$ means that higher bid amount induces a lower probability of saying "yes" to an offered bid. From Equation (1), the spike is derived as $\left[1+\exp \left(\gamma_{0}\right)\right]^{-1}$. The estimate for the spike is calculated as 0.594 and statistically significant. Since the spike implies the possibility of the interviewees having zero WTP, the estimated spike should not be significantly different from the sample ratio of zero WTP (59.5\%). This is the case with our study.

Table 2. Estimation results of the model.

\begin{tabular}{|c|c|}
\hline Variables & Estimates $^{d}$ \\
\hline Constant & $-0.379(-5.90) \#$ \\
\hline Bid amount ${ }^{a}$ & $-3.411(-19.07) \#$ \\
\hline Spike & $0.594(38.27) \#$ \\
\hline Mean additional WTP per $\mathrm{m}^{2}$ & KRW 0.46 million (USD 424) \\
\hline$t$-value & $15.73^{\#}$ \\
\hline $95 \%$ confidence interval ${ }^{b}$ & KRW 0.41 to 0.53 million (USD 364 to 455 ) \\
\hline $99 \%$ confidence interval ${ }^{b}$ & KRW 0.40 to 0.55 million (USD 364 to 485 ) \\
\hline Sample size & 1000 \\
\hline Log-likelihood & -1057.30 \\
\hline Wald statistic ( $p$-value $)^{\mathrm{c}}$ & $247.41(0.000)$ \\
\hline
\end{tabular}

Notes: ${ }^{\text {a }}$ The unit is tens of thousands of Korean won and the exchange rate was USD 1.0 = KRW 1132 at the time of the survey. ${ }^{b}$ It is calculated by the use of the parametric bootstrapping method given in Krinsky and Robb [28]. ${ }^{c}$ It is computed under the null hypothesis of all the parameters' being jointly zero. ${ }^{d}$ The values reported in parentheses beside the coefficient estimates are $t$-values. ${ }^{\#}$ implies statistical meaningfulness at the $1 \%$ level.

Table 2 also provides an estimate of average WTP calculated using Equation (3). The average WTP has the value of KRW 0.46 million (USD 424) per $\mathrm{m}^{2}$ and statistical meaningfulness. It is desirable to calculate its confidence interval to explicitly take into account the uncertainty concerning the calculation of the point estimate. The $95 \%$ confidence interval computed adopting the parametric bootstrapping method presented in Krinsky and Robb [28] is KRW 0.41 to 0.53 million (USD \$364 to \$455) per $\mathrm{m}^{2}$.

\subsection{Reflection of Covariates}

Covariates mean the factors that can have an effect on the probability of saying "yes" to a given bid. Usually, the interviewees' characteristics are used as covariates. Usually, the covariates are reflected in the model by inserting them into $\gamma_{0}$ in Equation (1). We consider four variables: education, income, head, and gender. The variables are explained in Table 3. Therefore, a positive sign of the coefficient for a variable implies that the greater the value of the variable, the higher the probability of reporting "yes" to a presented bid. 
Table 3. Description of the variables used for covariates.

\begin{tabular}{cccc}
\hline Variables & Definitions & Mean & Standard Deviation \\
\hline Education & The respondent's educational level in years & 14.04 & 2.27 \\
\hline Income & $\begin{array}{c}\text { The respondent's household's monthly income before } \\
\text { tax deduction (unit: million Korean won })\end{array}$ & 4.80 & 5.99 \\
\hline Head & $\begin{array}{c}\text { Whether the respondent is the head of household } \\
(1=\text { head; } 0=\text { otherwise })\end{array}$ & 0.55 & 0.50 \\
\hline Gender & The respondent's gender $(0=$ male; $1=$ female $)$ & 0.50 & 0.50 \\
\hline
\end{tabular}

The estimation results of the model with covariates are shown in Table 4. The estimate for $\gamma_{1}$ is expected to be negative and statistically meaningful. The coefficient estimates for other variables are all statistically significant. The respondent's education level is positively related to the probability of reporting "yes" to a given bid. Similarly, wealthier interviewees are more inclined to accept the payment of a proposed bid than less wealthy interviewees.

Table 4. Estimation results of the spike model with covariates.

\begin{tabular}{|c|c|c|}
\hline Variables $^{a}$ & Estimates & $t$-Values \\
\hline Constant & -2.6080 & $-6.21 *$ \\
\hline Bid amount ${ }^{b}$ & -3.5066 & $-19.12 *$ \\
\hline Education & 0.1424 & $4.75 *$ \\
\hline Income & 0.0581 & $2.05 *$ \\
\hline Head & 0.5515 & 1.80 * \\
\hline Gender & -0.7127 & $-2.32 *$ \\
\hline Spike & 0.4679 & $29.47 *$ \\
\hline Mean additional WTP per $\mathrm{m}^{2}$ & \multicolumn{2}{|c|}{ KRW 0.45 million (USD 394) } \\
\hline$t$-value & \multicolumn{2}{|c|}{$15.63^{* *}$} \\
\hline $95 \%$ confidence interval ${ }^{c}$ & \multicolumn{2}{|c|}{ KRW 0.40 to 0.51 million (USD 364 to 455 ) } \\
\hline $99 \%$ confidence interval ${ }^{c}$ & \multicolumn{2}{|c|}{ KRW 0.38 to 0.53 million (USD 333 to 464 ) } \\
\hline Wald statistic ( $p$-value $)^{\mathrm{d}}$ & \multicolumn{2}{|c|}{$491.94(0.000)$} \\
\hline Log-likelihood & \multicolumn{2}{|c|}{-1036.54} \\
\hline Number of observations & \multicolumn{2}{|c|}{1000} \\
\hline
\end{tabular}

Notes: ${ }^{a}$ Table 3 explains the variables. ${ }^{\mathrm{b}}$ The unit is tens of thousands of Korean won and the exchange rate was USD 1.0 = KRW 1132 at the time of the survey. ${ }^{\mathrm{c}}$ It is calculated by the use of the parametric bootstrapping method given in Krinsky and Robb [28]. ${ }^{\mathrm{d}}$ It is computed under the null hypothesis of all the parameters' being jointly zero. *and ** indicate statistical meaningfulness at the $10 \%$ and $1 \%$ levels, respectively.

\subsection{Discussion of the Results}

To look into consumers' preferences for NZEAs, we estimated a mean additional WTP for a NZEA over a conventional apartment. The most important issue in the estimation process is whether the sample represents the population. Thus, whether some variables for the sample are similar to those for the population or not should be examined. In this regard, the ratio of female respondents, and the household's monthly income are looked into here. The sample averages for the variables were $50.0 \%$, and KRW 4.80 million. The population averages were 50.0\%, KRW 4.50 million when the survey was conducted [24]. Interestingly, it seems that there are no significant gaps between the two values for each variable. This finding makes the representativeness of our sample even stronger.

How to select covariates may influence the mean WTP estimate. Therefore, the mean WTP estimate found in the model with no covariates is used. The mean additional WTP for a NZEA is estimated to be KRW 0.46 million (USD 424) per $\mathrm{m}^{2}$, which is statistically meaningful at the $1 \%$ level. This corresponds to $17.0 \%$ of the price of a conventional apartment per $\mathrm{m}^{2}$ (KRW 2.76 million or USD 2436). Consumers' WTP for a NZEA over a conventional apartment in South Korea is illustrated in Figure 1. The 95\% and the 99\% confidence intervals for the mean additional WTP for NZEA are KRW 0.41 to 0.53 million (USD \$364 to \$455) and KRW 0.40 to 0.55 million (USD 364 to 485) per $\mathrm{m}^{2}$, 
respectively. In this regard, it can be concluded that the households in South Korea place a significant value on a NZEA over a conventional apartment. A summary of the procedures of conducting this study is shown in Figure 2.

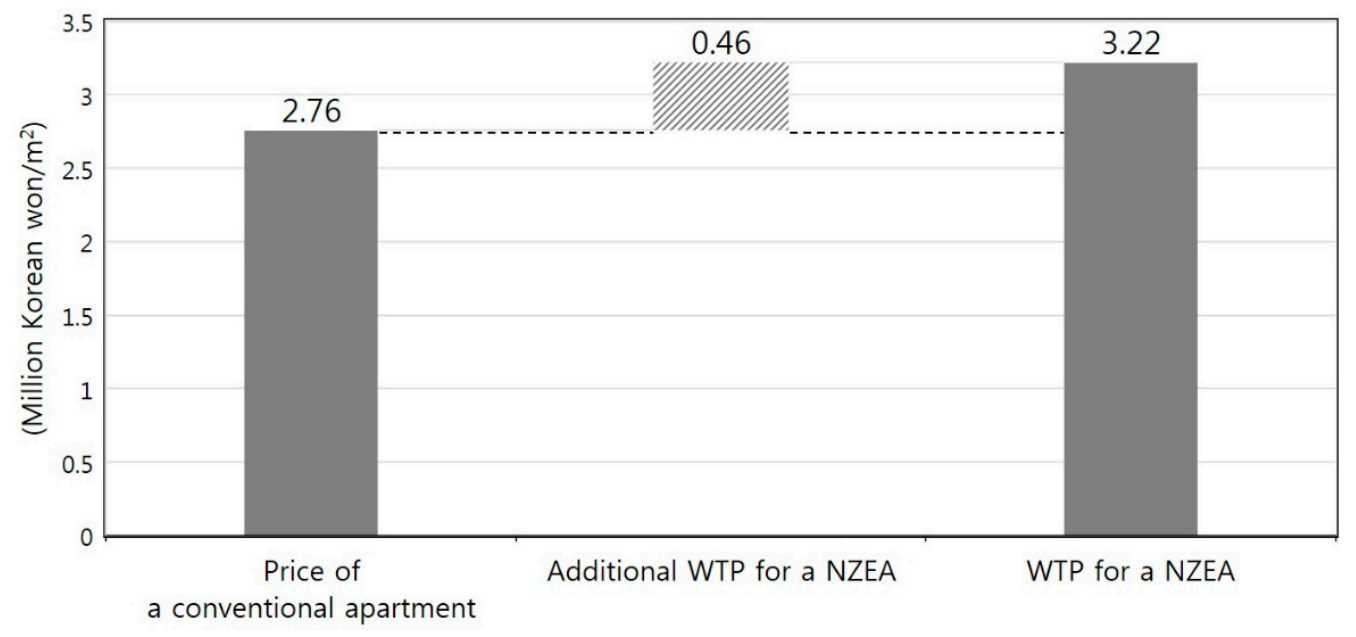

Figure 1. Consumers' willingness to pay (WTP) for a net zero energy apartment (NZEA) over a conventional apartment in South Korea.

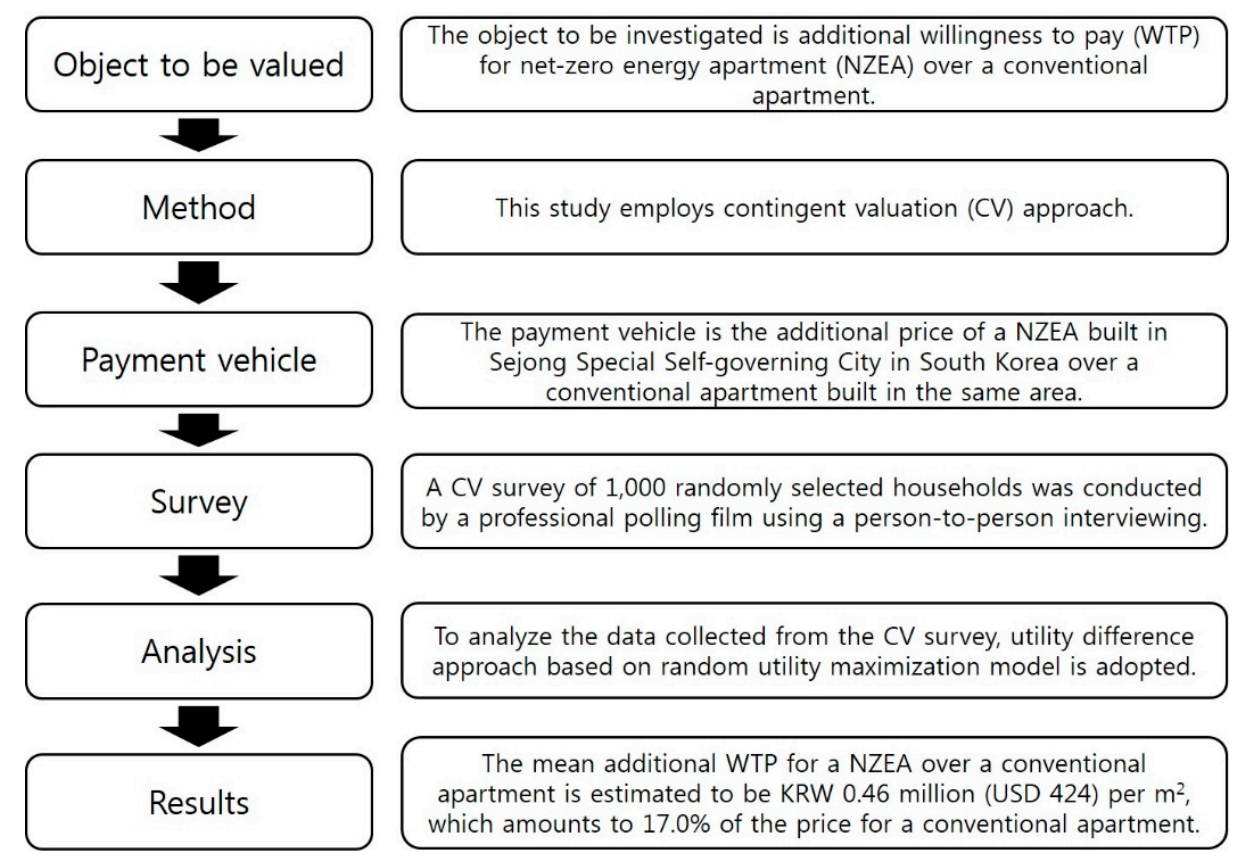

Figure 2. Summary of the procedure of conducting this study.

The additional WTP reflects the present values of the consumers' future cost savings related to energy expenditures. If the additional cost involved in building a NZEA that can significantly mitigate GHG emissions by adding energy saving technology and renewable energy production facility is less than the additional WTP plus the environmental benefits concerning the reduction of GHG and air pollutants emissions, expanding the supply of the NZEAs can be successfully implemented. If not, further action is needed for successful expansion of the NZEAs. For example, it is related to granting subsidies for renewable energy production facilities, extending the lending limits of housing city funds. In addition, the governments can offer a variety of tax credits and other incentives to expand the NZEAs. For instance, it is recommended that subsidies be paid as an incentive to companies that 
develop renewable energy production facilities and use construction materials that reduce energy consumption. Furthermore, the information on the WTP found in the article can be used to determine the level of tax relief, tax deductions, or subsidies needed to expand the supply of the NZEAs.

\section{Conclusions}

In South Korea, as GHG emission has increased recently, there is concern about climate change. Particularly, one quarter of the nation's GHG emissions are from the building sector. For the purpose of abating GHG emissions, we should reduce the energy consumption of buildings. The South Korean government, therefore, has planned to expand the supply of a NZEAs. This study applied a CV technique to assessing the consumers' additional WTP for a NZEA over a conventional apartment. The estimate for the mean WTP for the NZEA was KRW 0.46 million (USD 424) per $\mathrm{m}^{2}$. It has statistical meaningfulness at the $1 \%$ level and the sample also represented the population well. Considering that the apartment sale price was KRW 2.76 million per $\mathrm{m}^{2}$ at the time of the survey [24], consumers were willing to pay $17.0 \%$ more to live in the NZEA.

We also presented the mean WTP estimate from the model with covariates and its $95 \%$ confidence interval in Table 4. How much does the WTP change when considering the covariates provide more details about policies and, in particular, for informing the population about policy measures as they can be more targeted towards different societal groups? The mean WTP obtained was KRW 0.45 million (USD 394) and its $95 \%$ confidence interval was estimated as KRW 0.40 to 0.51 million. To check whether the mean WTP estimate from the model without the covariates is different from that from the model with the covariates, we applied a simple test. The null hypothesis is that they do not differ. Given that the 95\% confidence intervals for the mean WTP estimates from the models with the covariates and without the covariates do overlap, thus, the null hypothesis cannot be rejected at the 5\% level, which implies that they do not significantly differ.

These results are a useful baseline for understanding the potential implications of NZEAs. The government and industry should be aware of how much potential consumers' additional WTP for a NZEA is. For example, it is encouraged to expand the supply of the NZEAs because the consumers gave higher value to a NZEA than a conventional apartment. This article added a contribution to the current literature by deriving the household WTP for living in a NZEA rather than a conventional apartment. The study provided empirical evidence that the $\mathrm{CV}$ approach, theoretically grounded in microeconomics, could be successfully utilized in measuring the additional WTP.

Furthermore, the factors affecting the public trust in the policy need to be identified and investigated. This is because if people do not have trust in the policy enforcement, it cannot succeed. Thus, the government should consider which factors influence and how much the factors affect people's trust when designing a policy of expanding a supply of NZEAs. It may be useful to examine how the public value varies as time passes by conducting the CV survey every year for some years and analyzing the $\mathrm{CV}$ data. Investigating how much the value changes across regions and identifying other geographic factors which affect the value are also a good research topic. Comparing the findings from this study with those from other studies for foreign countries and analyzing the gap between the two enable us to obtain new insight into the WTP estimate. These works can provide us with a new point of view concerning the additional WTP.

Author Contributions: All of the authors played an important role in the preparation of this paper. J.-H.K. wrote most of the paper; H.-J.K. conducted the empirical analysis; and S.-H.Y. took charge of making the survey questionnaire and gathering the data.

Acknowledgments: This work was supported by the Korea Institute of Energy Technology Evaluation and Planning (KETEP) and the Ministry of Trade, Industry and Energy (MOTIE) of the Republic of Korea (no. 20164030201060).

Conflicts of Interest: The authors declare no conflict of interest. 


\section{References}

1. Intergovernmental Panel on Climate Change. Climate Change 2014: Synthesis Report; IPCC: Geneva, Switzerland, 2014; p. 151.

2. OECD. OECD Environmental Performance Review: Korea 2017; OECD Publishing: Paris, France, 2017.

3. MOLIT. Policy Report: To Cope with Climate Change Zero Energy Building Promotion Plan. 2016. Available online: http:/ / www.molit.go.kr (accessed on 5 March 2018). (In Korean)

4. International Energy Agency. World Energy Outlook; OECD/IEA: Paris, France, 2016. Available online: www.iea.org (accessed on 5 March 2018).

5. AbuGrain, M.Y.; Alibaba, H.Z. Optimizing existing multistory building designs towards net-zero energy. Sustainability 2017, 9, 399. [CrossRef]

6. Bühler, D.; Schuetze, T.; Junge, R. Towards development of a label for zero emission buildings: A tool to evaluate potential zero emission buildings. Sustainability 2015, 7, 5071-5093. [CrossRef]

7. Koller, C.; Talmon-Gros, M.J.; Junge, R.; Schuetze, T. Energy toolbox-framework for the development of a tool for the primary design of zero emission buildings in European and Asian cities. Sustainability 2017, 9 , 2244. [CrossRef]

8. Marszal, A.J.; Heiselberg, P.; Bourrelle, J.S.; Musall, E.; Voss, K.; Sartori, I.; Napolitano, A. Zero Energy Building-A review of definitions and calculation methodologies. Energy Build. 2011, 43, 971-979. [CrossRef]

9. Wang, L.; Gwilliam, J.; Jones, P. Case study of zero energy house design in UK. Energy Build. 2009, 41, 1215-1222. [CrossRef]

10. Li, H.X.; Patel, D.; Al-Hussein, M.; Yu, H.; Gül, M. Stakeholder studies and the social networks of NetZero energy homes (NZEHs). Sustain. Cities Soc. 2018, 38, 9-17. [CrossRef]

11. Min, S.H.; Lim, S.Y.; Yoo, S.H. Consumer's willingness to pay a premium for eco-labeled LED TVs in Korea: A contingent valuation study. Sustainability 2017, 9, 814. [CrossRef]

12. Park, S.Y.; Lim, S.Y.; Yoo, S.H. The economic value of the national meteorological service in the Korean household sector: A contingent valuation study. Sustainability 2016, 8, 834. [CrossRef]

13. Lim, S.Y.; Kim, H.Y.; Yoo, S.H. Public willingness to pay for transforming Jogyesa Buddhist temple in Seoul, Korea into a cultural tourism resource. Sustainability 2016, 8, 900. [CrossRef]

14. Kim, H.Y.; Park, S.Y.; Yoo, S.H. Public acceptability of introducing a biogas mandate in Korea: A contingent valuation study. Sustainability 2016, 8, 1087. [CrossRef]

15. Wang, J.; Ge, J.; Ma, Y. Urban Chinese consumers' willingness to pay for pork with certified labels: A discrete choice experiment. Sustainability 2018, 10, 603. [CrossRef]

16. Yang, H.J.; Lim, S.Y.; Yoo, S.H. The environmental costs of photovoltaic power plants in South Korea: A choice experiment study. Sustainability 2017, 9, 1773. [CrossRef]

17. Vanstockem, J.; Vranken, L.; Bleys, B.; Somers, B.; Hermy, M. Do looks matter? A case study on extensive green roofs using discrete choice experiments. Sustainability 2018, 10, 309. [CrossRef]

18. Abdullah, S.; Jeanty, P.W. Willingness to pay for renewable energy: Evidence from a contingent valuation survey in Kenya. Renew. Sustain. Energy Rev. 2011, 15, 2974-2983. [CrossRef]

19. Guo, X.; Liu, H.; Mao, X.; Jin, J.; Chen, D.; Cheng, S. Willingness to pay for renewable electricity: A contingent valuation study in Beijing, China. Energy Policy 2014, 68, 340-347. [CrossRef]

20. Lim, K.M.; Lim, S.Y.; Yoo, S.H. Estimating the economic value of residential electricity use in the Republic of Korea using contingent valuation. Energy 2014, 64, 601-606. [CrossRef]

21. Champ, P.A.; Boyle, K.J.; Brown, T.C.A. Primer on Nonmarket Valuation; Kluwer Academic Publisher: Dordrecht, The Netherlands, 2004.

22. Cooper, J.C.; Hanemann, W.M.; Signorello, G. One and one-half bound dichotomous choice contingent valuation. Rev. Econ. Stat. 2002, 84, 742-750. [CrossRef]

23. Kriström, B. Spike model in contingent valuation. Am. J. Agric. Econ. 1997, 79, 1013-1023. [CrossRef]

24. Statistics Korea. Available online: http:/ / kosis.kr (accessed on 2 March 2018).

25. Hanemann, W.M. Welfare evaluations in contingent valuation experiments with discrete responses. Am. J. Agric. Econ. 1984, 66, 332-341. [CrossRef]

26. Hanemann, W.M.; Loomis, J.; Kanninen, B.J. Statistical efficiency of double-bounded dichotomous choice contingent valuation. Am. J. Agric. Econ. 1991, 73, 1255-1263. [CrossRef] 
27. Johnston, R.J.; Boyle, K.J.; Adamowicz, W.; Bennett, J.; Brouwer, R.; Cameron, T.A.; Hanemann, W.M.; Hanley, N.; Ryan, M.; Scarpa, R.; et al. Contemporary guidance for stated preference studies. J. Assoc. Environ. Resour. Econ. 2017, 4, 319-405. [CrossRef]

28. Krinsky, I.; Robb, A.L. On approximating the statistical properties of elasticities. Rev. Econ. Stat. 1986, 68, 715-719. [CrossRef] 